\title{
Ovarian Sex Cord Tumor with Annular Tubules
}

National Cancer Institute

\section{Source}

National Cancer Institute. Ovarian Sex Cord Tumor with Annular T ubules. NCI Thesaurus. Code C4208.

An ovarian sex cord-stromal tumor characterized by the presence of Sertoli cells forming annular tubules. It may be associated with Peutz-Jeghers syndrome. Cases associated with Peutz-Jeg hers syndrome have followed a benign clinical course. Cases which are not associated with Peutz-Jeghers syndrome have been reported having a clinically malignant course. 